\title{
Assessment of the Compatibility of the Real-World Nonvalvular Atrial Fibrillation Patients in Turkey with the Study Population of Phase 3 Novel Oral Anticoagulant Trials: An Auxiliary Study of NOAC-TR
} \author{
${ }^{4}$ Department of Cardiology, Hitit University School of Medicine, Corum, Turkey \\ ORCID: \\ Sadik Volkan Emren: https://orcid.org/0000-0002-7652-1123 \\ Mehdi Zoghi: https://orcid.org/0000-0002-8156-2675 \\ Ugur Karagöz: https://orcid.org/0000-0001-9748-5136 \\ Sinan Inci: https://orcid.org/0000-0002-4576-128X \\ Gönül Açiksari: https://orcid.org/0000-0002-8380-3065 \\ Lütfü Bekar: https://orcid.org/0000-0002-3920-1382 \\ Zeynep Yapan Emren: https://orcid.org/0000-0002-5508-9474 \\ Oktay Ergene: https://orcid.org/0000-0003-1775-4063
}

Sadik Volkan Emren, Mehdi Zoghi', Ugur Karagöz, Sinan Inci², Gönül Açiksari³, Lütfü Bekar, Zeynep Yapan Emren ${ }^{5}$, Oktay Ergene $^{6}$

Department of Cardiology, School of Medicine, Katip Çelebi University, 'Department of Cardiology, Ege University School of Medicine, ${ }^{5}$ Department of Cardiology, Çigli State Hospital, ${ }^{6}$ Department of Cardiology, School of Medicine, Dokuz Eylül University, Izmir, ${ }^{2}$ Department of Cardiology, Aksaray University School of Medicine, Aksaray, Central Anatolia, ${ }^{3}$ Department of Cardiology, School of Medicine, Göztepe Training and Research Hospital, Istanbul Medeniyet University, Istanbul,

\section{Abstract}

Introduction: Although the indication of novel oral anticoagulant (NOAC) treatment in atrial fibrillation (AF) is comparatively similar, Phase 3 NOAC trials have variable inclusion criteria that differentiate each other and also from the real-world population. Aim: We aim to investigate the similarity between real-world nonvalvular AF patients and the population of Phase 3 NOAC trials in terms of eligibility. Methods: A total of 2802 patients using rivaroxaban, dabigatran, and apixaban were retrospectively evaluated. All the patients met the exclusion criteria of NOAC Phase 3 trials. These patient population were compared with the population of Phase 3 rivaroxaban (ROCKET-AF), dabigatran (RELY), apixaban (ARISTOTLE), and edoxaban (ENGAGE) trials in terms of inclusion criteria. Furthermore, the patients were stratified on the basis of $\mathrm{CHA}_{2}-\mathrm{DS}_{2}-\mathrm{VASC}$ is enaogh score. Results: The proportion of population who met the eligible criteria for ARISTOTLE trial (91\%) was different from that of RELY (78\%), ROCKET-AF (50\%), and ENGAGE $(61 \%)$ trials $(P<0,001)$. For the population at intermediate risk (CHA DS $_{2}-$ VASc score $\geq 1$ ), the proportion which met the inclusion criteria for RE-LY trial (99\%) was different from that of ARISTOTLE (91.2\%), ROCKET-AF (50\%), and ENGAGE trials $(61 \%)(P<0.001)$. For the population at high risk $\left(\mathrm{CHA}_{2} \mathrm{DS}_{2}-\mathrm{VASc}\right.$ score $\left.\geq 2\right)$, the proportion which met the inclusion criteria was as follows: $94 \%$ for ARISTOTLE, $83 \%$ for RELY, $65 \%$ for ENGAGE, and 53\% for ROCKET-AF trials $(P<0.001)$. In this population, $38 \%$ of patients using rivaroxaban, $46 \%$ of patients using dabigatran, and $12 \%$ patients of using apixaban did not meet the inclusion criteria for the ROCKET-AF, RE-LY, and ARISTOTLE trials, respectively. Conclusion: Eligibility of the real-world population for NOAC trials is variable. A considerable number of real-world patients using NOAC do not meet the inclusion criteria of the corresponding drug.

Keywords: Atrial fibrillation, $\mathrm{CHA}_{2} \mathrm{DS}_{2}-\mathrm{VASc}$ score, $\mathrm{CHADS}_{2}$ score, novel oral anticoagulants

Received: 05-08-2019 Revision: 09-09-2019 Accepted: 16-10-2019

Published Online: 13-02-2020

\begin{tabular}{|l|l|}
\hline \multicolumn{2}{|c|}{ Access this article online } \\
\hline Quick Response Code: & $\begin{array}{l}\text { Website: } \\
\text { http://www.ijcva.com }\end{array}$ \\
& \\
& \\
\end{tabular}

Address for correspondence: Dr. Sadik Volkan Emren Department of Cardiology, School of Medicine, Katip Celebi University, 35160 Izmir, Turkey. E-mail: vemren@hotmail.com

This is an open access journal, and articles are distributed under the terms of the Creative Commons Attribution-NonCommercial-ShareAlike 4.0 License, which allows others to remix, tweak, and build upon the work non-commercially, as long as appropriate credit is given and the new creations are licensed under the identical terms.

For reprints contact: reprints@medknow.com

How to cite this article: Emren SV, Zoghi M, Karagöz U, Inci S, Açiksari G, Bekar L, et al. Assessment of the compatibility of the real-world nonvalvular atrial fibrillation patients in Turkey with the study population of Phase 3 novel oral anticoagulant trials: An auxiliary study of NOAC-TR. Int J Cardiovasc Acad 2020;6:12-5. 


\section{INTRODUCTION}

Atrial fibrillation (AF) is the most common sustained arrhythmia which is associated with morbidity and mortality by causing stroke and thromboembolism in particular. ${ }^{[1]}$ Oral anticoagulants (OACs) have become the mainstay treatment for the prevention of thromboembolism in patients with AF. For many decades, Vitamin K antagonists (VKAs) have been the only available OAC drugs. ${ }^{[2]}$ Development of new OAC NOACs including rivaroxaban, apixaban, edoxaban, and dabigatran has created a paradigm shift in AF treatment. In Phase 3 trials, NOACs have been demonstrated favorable outcomes over VKA regarding efficacy and safety in nonvalvular AF (NVAF) population. ${ }^{[3-6]}$ Moreover, advancement of NOAC therapy has provided many facilities and avoided many flaws of VKA such as drug and food interaction, frequent monitoring, difficulty in dose adjustment, and variability of anticoagulant effect. ${ }^{[7,8]}$ Therefore, the NOAC market sharing has been growing rapidly for the last years. ${ }^{[9]}$

While the indication for AF treatment is same among NOACs, eligibility criteria in Phase 3 NOAC trials, such as ARISTOTLE, RE-LY, ROCKET-AF, ENGAGE-TIMI-AF, are comparatively different. ${ }^{[10]}$ Thus, Phase 3 NOAC trials represent different groups of $\mathrm{AF}$ patients. It is not clearly known whether real-world AF population using NOAC were eligible for the NOAC trials.

On the basis of these data, we aimed to assess the compatibility of the real-world AF patients with the study population in Phase 3 NOAC trials in terms of eligibility criteria.

\section{Methods}

We retrospectively analyzed the database of NOAC-TR study which was conducted between September 1,2015, and February 28, 2016. ${ }^{[8]}$ In NOAC-TR study, the patients were included if they had the following criteria: $>18$ years old; nonvalvular atrial fibrillation (NVAF) without end-stage renal failure; and use of any NOAC such as rivaroxaban, apixaban, edoxaban, and dabigatran. All these patients had used warfarin before they were given NOAC an account of the reimbursement conditions of the National Health Insurance. A total of 2802 patients were evaluated for the eligibility criteria of ARISTOTLE, ${ }^{[3]} \mathrm{RE}-\mathrm{LY},{ }^{[4]}$ ROCKET-AF, ${ }^{[5]}$ and ENGAGE-TIMI-AF ${ }^{[6]}$ trials. We got the information of patients including age, gender, hypertension, coronary artery disease, heart failure, diabetes mellitus, peripheral arterial disease, cerebrovascular disease (stroke and transient ischemic attack), chronic renal failure, nonsteroidal anti-inflammatory and acetylsalicylic acid use, previous bleeding especially gastrointestinal and intracranial bleeding, and types of NOAC they use.

Eligibility of patients for NOAC trials was also evaluated by stratifying to the Congestive heart failure, Hypertension, Age $\geq 75$ years, Diabetes mellitus (CHADS) ( 1 point for the presence of each, and Stroke/transient ischemic attack [2 points]) $\mathrm{CHADS}_{2}$ and $\mathrm{CHA}_{2} \mathrm{DS}_{2}-\mathrm{VASc}$ score respectively
(Congestive heart failure [1 point], Hypertension [1 point], Age $\geq 75$ years [2 point], Diabetes mellitus [1 point], Stroke/ transient ischemic attack [2 points]; Vascular disease (history of myocardial infarction, presence of complex aortic plaque, or peripheral artery disease [ 1 point], age $65-74$ years [ 1 point], and female sex [1 point]). Finally, we also determined the proportion of patients using inappropriate NOAC because of being ineligible for the corresponding NOAC trial. This study was approved by the ethical committee.

\section{Statistical analysis}

Statistical analysis was performed using the SPSS (version 15.0, SPSS Inc., Chicago, Illinois, USA) software package. Continuous variables were expressed as mean \pm standard deviation (mean $\pm \mathrm{SD}$ ), and categorical variables were expressed as percentage (\%). Chi-square test was used to compare the percentage of patients eligible for ARISTOTLE, RE-LY, ROCKET-AF, and ENGAGE-AF trials. A two-tailed $P<0.05$ was considered statistically significant.

\section{RESULTS}

The demographic and clinical characteristics of the patients are shown in Table 1. The mean age of the NVAF population was $70 \pm 10.5$ years, and a female predominance (1661 [59\%]) was observed. Hypertension was the most common additional cardiovascular risk factor (79\%). Only $12 \%$ of the patients had a history of cerebrovascular event. The most commonly used NOAC was dabigatran (44\%) followed by rivaroxaban (38\%) and apixaban (17\%). The mean $\mathrm{CHA}_{2} \mathrm{DS}_{2}-\mathrm{VASC}$ score was $3.45 \pm 1.4$, and the mean $\mathrm{CHADS}_{2}$ score was $1.9 \pm 1.14$. The proportion of population who met the eligible criteria for ARISTOTLE trial (91\%) was different from that of RELY (78\%), ROCKET-AF (50\%), and ENGAGE (61\%) trials $(P<0,001)$. For the population at intermediate and high risk $\left(\mathrm{CHA}_{2} \mathrm{DS}_{2}-\mathrm{VASc}\right.$ score $\left.\geq 1\right)$, the proportion which met the inclusion criteria for RE-LY trial (99\%) was different from that of ARISTOTLE (91.2\%), ROCKET-AF (50\%), and ENGAGE trials $(61 \%)(P<0.001)$. For the population at high risk $\left(\mathrm{CHA}_{2} \mathrm{DS}_{2}-\mathrm{VASc}\right.$ score $\left.\geq 2\right)$, the proportion which met the inclusion criteria was as follows: $94 \%$ for ARISTOTLE, $83 \%$ for RELY, $65 \%$ for ENGAGE, and $53 \%$ for ROCKET-AF trials $(P<0.001)$ [Table 2].

When stratifying patients according to the CHADS score, for intermediate and high risk $\left(\mathrm{CHADS}_{2} \geq 1\right)$, the proportion which met the inclusion criteria for ARISTOTLE trial (100\%) was different from that of RE-LY $(86 \%)$, ROCKET-AF $(55 \%)$, and ENGAGE trials $(67 \%)(P<0.001)$. For high-risk population $\left(\mathrm{CHADS}_{2} \geq 2\right)$, the proportion which met the inclusion criteria for ARISTOTLE and ENGAGE trials $(100 \%)$ was different from that of RE-LY (94\%) and ROCKET-AF $(81 \%)$ trials $(P<0,001)$.

In this population, $38 \%$ of patients using rivaroxaban, $46 \%$ of patients using dabigatran, and $12 \%$ patients using apixaban did not meet the inclusion criteria for ROCKET-AF, RE-LY, and ARISTOTLE trials, respectively [Figure 1]. 


\section{Discussion}

The results of this study show that eligibility of the real-world population to Phase 3 trials is significantly different. According to our findings, ARISTOTLE trial most commonly represents real-world population in Turkey on the basis of eligibility criteria. Yet, with the increasing risk of thromboembolism, higher number of patients become eligible for all over NOAC trials. Although indications are same for all NOACs, a

\begin{tabular}{|c|c|}
\hline Age (years), mean \pm SD & $70 \pm 10.5$ \\
\hline Age $\geq 65$ years, $n(\%)$ & $2018(75)$ \\
\hline Age $\geq 75$ years, $n(\%)$ & $1090(39)$ \\
\hline Gender, Female, $n(\%)$ & $1661(59)$ \\
\hline Hypertension, $n(\%)$ & $2200(79)$ \\
\hline Diabetes mellitus, $n(\%)$ & $686(25)$ \\
\hline Heart failure, $n(\%)$ & $712(25)$ \\
\hline Coronary heart disease, $n(\%)$ & $768(27)$ \\
\hline Cerebrovascular event, $n(\%)$ & $343(12)$ \\
\hline Peripheral arterial disease, $n(\%)$ & $85(3)$ \\
\hline Chronic renal failure, $n(\%)$ & $200(7)$ \\
\hline NSAID use, $n(\%)$ & $495(18)$ \\
\hline ASA use, $n(\%)$ & $352(13)$ \\
\hline \multicolumn{2}{|l|}{ NOAC, $n(\%)$} \\
\hline Dabigatran & $1234(44)$ \\
\hline Apixaban & $486(17)$ \\
\hline Rivaroxaban & $1075(38)$ \\
\hline Gastrointestinal hemorrhage, $n(\%)$ & $67(2.4)$ \\
\hline Intracranial hemorrhage, $n(\%)$ & $15(1)$ \\
\hline $\mathrm{CHA}_{2} \mathrm{DS}_{2}$-VASCc score, mean $\pm \mathrm{SD}$ & $3.45 \pm 1.4$ \\
\hline $\mathrm{CHA}_{2} \mathrm{DS}_{2}$-VASCc score $\geq 1, n(\%)$ & $2802(100)$ \\
\hline $\mathrm{CHA}_{2} \mathrm{DS}_{2}-\mathrm{VASCc}$ score $\geq 2, n(\%)$ & $2632(94)$ \\
\hline $\mathrm{CHADS}_{2}$ score, mean $\pm \mathrm{SD}$ & $1.9 \pm 1.14$ \\
\hline $\mathrm{CHADS}_{2} \geq 1, n(\%)$ & $2554(91)$ \\
\hline $\mathrm{CHADS}_{2} \geq 2, n(\%)$ & $1712(61)$ \\
\hline \multicolumn{2}{|c|}{$\begin{array}{l}\text { ASA: Acetylsalicylic acid, NOAC: Novel oral anticoagulants, } \\
\text { NSAID: Nonsteroidal anti-inflammatory drug, } \mathrm{CHADS}_{2} \text { score: } \\
\text { Congestive heart failure, Hypertension, Age } \geq 75 \text { years, Diabetes mellitus } \\
\text { ( } 1 \text { point for the presence of each), and Stroke/transient ischemic attack } \\
\text { ( } 2 \text { points), } \mathrm{CHA}_{2} \mathrm{DS} \mathrm{S}_{2}-\mathrm{VASc} \text { score } \text { : Congestive heart failure ( } 1 \text { point), } \\
\text { Hypertension ( } 1 \text { point), Age } \geq 75 \text { years ( } 2 \text { points), Diabetes mellitus } \\
\text { (1 point), Stroke/transient ischemic attack ( } 2 \text { points), Vascular disease } \\
\text { history of myocardial infarction, presence of complex aortic plaque, or } \\
\text { peripheral artery disease ( } 1 \text { point), age } 65-74 \text { years ( } 1 \text { point), female sex } \\
\text { ( } 1 \text { point), SD: Standard deviation }\end{array}$} \\
\hline
\end{tabular}

considerable number of patients who use NOAC do not meet the eligibility criteria of the corresponding trial.

There are several factors that make the NOAC studies variable in terms of inclusion and exclusion criteria. Yet, the main determinant factor is supposed to be the inclusion criteria. ROCKET and ENGAGE trials included high thromboembolic risk patients which required at least two points in the $\mathrm{CHADS}_{2}$ score. However, the ARISTOTLE trial included patients with only one thromboembolic risk factor. Besides, in the ROCKET trial, the patients were given 1 point if they had more severe heart failure (ejection fraction $[\mathrm{EF}] \leq 35 \%$ ) compared to those in RE-LY and ARSITOTLE trials who were given 1 point if they had $E F \leq 40$. Our real-world population consisted of relatively younger population as only $39 \%$ were aged $\geq 75$ years. Hence, most of them got no points for $\mathrm{CHADS}_{2}$ score regarding age. The history of stroke rate was considerably low. Moreover, our population had lower thromboembolic risk (mean $\mathrm{CHADS}_{2}$ score of 1.9) compared to ROCKET-AF (mean $\mathrm{CHADS}_{2}$ risk score of 3.48), RE-LY (mean $\mathrm{CHADS}_{2}$ risk score of 2.1), ARISTOTLE (mean $\mathrm{CHADS}_{2}$ risk score of 2.2), and ENGAGE (mean $\mathrm{CHADS}_{2}$ risk score of 2.2) trials. Another main factor was the selection of thromboembolic risk score. Although Phase 3 NOAC trials used CHADS score for risk stratification, the current guidelines recommend to use $\mathrm{CHA}_{2} \mathrm{DS}_{2}$-VASc score to determine the commensal of oral anticoagulation. ${ }^{[2]}$ Some risk factors such as vascular disease,

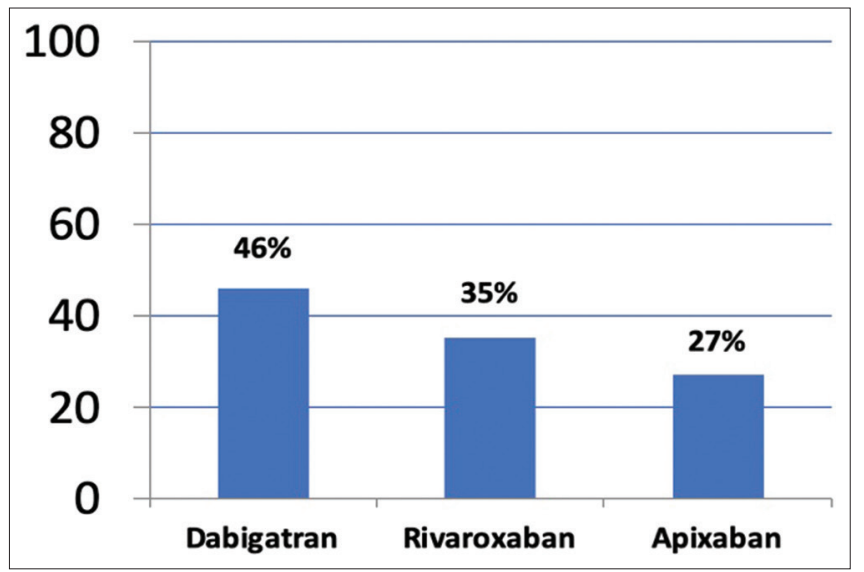

Figure 1: Percentage of patients misusing novel oral anticoagulants based on the eligibility criteria of the corresponding trial

\section{Table 2: Representativeness of the novel oral anticoagulants trials to real-world population stratified by risk scores}

\begin{tabular}{|c|c|c|c|c|c|}
\hline & $n$ & ARISTOTLE, $n$ (\%) & RE-LY, $\boldsymbol{n}(\%)$ & ROCKET, $\boldsymbol{n}(\%)$ & ENGAGE, $n(\%)$ \\
\hline Total & 2802 & $2554(91)$ & $2199(78)$ & $1392(50)$ & $1712(61)$ \\
\hline $\mathrm{CHADS}_{2} \geq 1$ & 2554 & $2554(100)$ & $2188(86)$ & $1392(55)$ & $1712(67)$ \\
\hline $\mathrm{CHA}_{2} \mathrm{DS}_{2}-\mathrm{VASc} \geq 1$ & 2802 & $2554(91)$ & $2781(99)$ & $1392(50)$ & $1712(61)$ \\
\hline $\mathrm{CHADS}_{2} \geq 2$ & 1712 & $1712(100)$ & $1604(94)$ & $1392(81)$ & $1712(100)$ \\
\hline $\mathrm{CHA}_{2} \mathrm{DS}_{2}-\mathrm{VASc} \geq 2$ & 2632 & $2468(94)$ & $2181(83)$ & $1384(53)$ & $1703(65)$ \\
\hline
\end{tabular}

CHADS $_{2}$ score: Congestive heart failure, Hypertension, Age $\geq 75$ years, Diabetes mellitus (1 point for the presence of each), and Stroke/transient ischemic attack (2 points), $\mathrm{CHA}_{2} \mathrm{DS}_{2}$-VASCc score: Congestive heart failure (1 point), Hypertension (1 point), Age $\geq 75$ years ( 2 points), Diabetes mellitus (1 point), Stroke/transient ischemic attack (2 points), Vascular disease history of myocardial infarction, presence of complex aortic plaque, or peripheral artery disease (1 point), age $65-74$ years (1 point), female sex (1 point) 
$>65$ years, and female gender do not play a role in $\mathrm{CHADS}_{2}$ score, but play in $\mathrm{CHA}_{2} \mathrm{DS}_{2}-\mathrm{VASc}$ score. These variables were significantly prevalent in our population.

There are also other studies which investigate the representativeness of the NOAC trials to real-world population. Lee et al. found that the study population in RE-LY (64\%) and ARISTOTLE (61\%) trials were more compatible than that of ROCKET-AF (48\%) trial to real-world AF patients in the United Kingdom health-care database. ${ }^{[11]}$ Yoon et al. investigated the eligibility of patients with and without stroke to NOAC trials. Although they did not make statistical comparison, the ARISTOTLE trial (72.8\%) was most eligible to real-world patients with stroke than RE-LY (65.6\%), ROCKET (64.8\%), and ENGAGE (57.4\%) trials. Furthermore, the most representative trial to nonstroke AF patients was ARISTOTLE (67.3\%) followed by RE-LY (45.1\%), ROCKET-AF (41\%), and ENGAGE (39\%) trials. ${ }^{[12]}$ Fanning et al. also demonstrated that ARISTOTLE and RE-LY trials were the most representative of hospitalized AF patients in Australia. ${ }^{[13]}$ Our findings were comparable to the above-mentioned studies as the ARISTOTLE trial was the most representative real-world AF population in Turkey. Regarding the eligibility, we also found that only few patients using apixaban did not comply with the ARISTOTLE trial. However, substantial number of patients using dabigatran and rivaroxaban did not comply with RE-LY and ROCAKET-AF trials, respectively. On the other hand, it should be kept in mind that divergences of eligibility of NOAC trials do not link to the indications and effectiveness of NOACs. All these patients meet the indications of NOACs.

\section{Study limitations}

This was a retrospective study; therefore, some data of the patients might be missed especially necessary for the exclusion criteria of NOAC trials. Another issue is that edoxaban was not given to patients at the time when this study was conducted as there was no reimbursement for edoxaban. Thus, the proportion of prescribed NOACs among patients might be changed thereafter.

\section{ConcLusion}

Eligibility of the real-world population for NOAC trials is variable. The most representative NOAC trial of real-world population is ARISTOTLE in Turkey. Besides, a considerable number of patients using NOAC are not eligible for the corresponding trial. Nevertheless, eligibility should not be confused with indication. It is obvious that variation of the eligibility criteria of the NOAC trials is not meant to change the indication of NOACs.

\section{Financial support and sponsorship}

Nil.

\section{Conflicts of interest}

There are no conflicts of interest.

\section{References}

1. Kirchhof P, Benussi S, Kotecha D, Ahlsson A, Atar D, Casadei B, et al. 2016 ESC guidelines for the management of atrial fibrillation developed in collaboration with EACTS. Eur J Cardiothorac Surg 2016;50:e1-88.

2. January CT, Wann LS, Calkins H, Chen LY, Cigarroa JE, Cleveland JC Jr., et al. 2019 AHA/ACC/HRS focused update of the 2014 AHA/ACC/HRS guideline for the management of patients with atrial fibrillation: A report of the American College of Cardiology/American Heart Association task force on clinical practice guidelines and the Heart Rhythm Society. J Am Coll Cardiol 2019;74:104-32.

3. Granger CB, Alexander JH, McMurray JJ, Lopes RD, Hylek EM, Hanna M, et al. Apixaban versus warfarin in patients with atrial fibrillation. N Engl J Med 2011;365:981-92.

4. Connolly SJ, Ezekowitz MD, Yusuf S, Eikelboom J, Oldgren J, Parekh A, et al. Dabigatran versus warfarin in patients with atrial fibrillation. N Engl J Med 2009;361:1139-51.

5. Patel MR, Mahaffey KW, Garg J, Pan G, Singer DE, Hacke W, et al. Rivaroxaban versus warfarin in nonvalvular atrial fibrillation. N Engl J Med 2011;365:883-91.

6. Giugliano RP, Ruff CT, Braunwald E, Murphy SA, Wiviott SD, Halperin JL, et al. Edoxaban versus warfarin in patients with atrial fibrillation. N Engl J Med 2013;369:2093-104.

7. Ansell J, Hirsh J, Hylek E, Jacobson A, Crowther M, Palareti G. Pharmacology and management of the Vitamin $\mathrm{K}$ antagonists: American College of Chest Physicians evidence-based clinical practice guidelines ( $8^{\text {th }}$ edition). Chest 2008;133:160S-98S.

8. Emren SV, Şenöz O, Bilgin M, Beton O, Aslan A, Taşkin U, et al. Drug adherence in patients with nonvalvular atrial fibrillation taking non-Vitamin $\mathrm{K}$ antagonist oral anticoagulants in Turkey: NOAC-TR. Clin Appl Thromb Hemost 2018;24:525-31.

9. Ergene $\mathrm{O}$. Where will non-Vitamin $\mathrm{K}$ oral anticoagulants stand beyond being standard of care in anticoagulation therapy? Int J Cardiovasc Acad 2019;5:75-9.

10. Camm AJ, Fox KA, Peterson E. Challenges in comparing the non-Vitamin $\mathrm{K}$ antagonist oral anticoagulants for atrial fibrillation-related stroke prevention. Europace 2018;20:1-1.

11. Lee S, Monz BU, Clemens A, Brueckmann M, Lip GY. Representativeness of the dabigatran, apixaban and rivaroxaban clinical trial populations to real-world atrial fibrillation patients in the United Kingdom: A cross-sectional analysis using the general practice research database. BMJ Open 2012;2. pii: e001768.

12. Yoon CH, Park YK, Kim SJ, Lee MJ, Ryoo S, Kim GM, et al. Eligibility and preference of new oral anticoagulants in patients with atrial fibrillation: Comparison between patients with versus without stroke. Stroke 2014;45:2983-8.

13. Fanning L, Ilomäki J, Bell JS, Dārziņš P. The representativeness of direct oral anticoagulant clinical trials to hospitalized patients with atrial fibrillation. Eur J Clin Pharmacol 2017;73:1427-36. 